\title{
ALOP-active learning in optics and photonics: a UNESCO's program spreading in Colombia through the National University
}

Catalina Ramírez-Gómez, Freddy Monroy-Ramírez

Catalina Ramírez-Gómez, Freddy Alberto Monroy-Ramírez, "ALOP-active learning in optics and photonics: a UNESCO's program spreading in Colombia through the National University," Proc. SPIE 9289, 12th Education and Training in Optics and Photonics Conference, 92890Y (17 July 2014); doi: 10.1117/12.2070744

Event: 12th Education and Training in Optics and Photonics Conference, 2013, Porto, Portugal 


\title{
ALOP-Active Learning in Optics and Photonics-A UNESCO's program spreading in Colombia through the National University Catalina Ramírez-Gómez ${ }^{\mathrm{a}}$, Freddy Alberto Monroy-Ramírez ${ }^{* a}$ \\ ${ }^{a}$ Science Faculty, National University of Colombia, Car. 30 \# 45-03 Build 405 of 218-Bogotá \\ Colombia
}

\begin{abstract}
The National University of Colombia is committed to the spreading of the UNESCO's ALOP program throughout the country by programming a series of workshops $(A L O P-N P H)$ to be held in each of its eight campuses. This huge effort is intended to contribute at a national scale to the training of high school teachers in new pedagogic methodologies. Furthermore, the ALOP Workshop has had large impact in the recently established Master's program on pedagogy of Sciences, a degree program addressed to middle and high school teachers, which has a current enrollment of more than 400 teachers from all over the country. In this paper we also describe the contributions of the team also ALOP-Colombia to the material and electronic devices used in optical transmission modules and data division multiplexing wavelength.

Keywords: Education, Active Learning, Optics, optical transmission, data division multiplexing wavelength.
\end{abstract}

\section{INTRODUCTION}

For several years, UNESCO has been developing the program ALOP - Active Learning in Optics and Photonics-in developing countries. The program aims to promote among teachers of secondary and early college levels, a new educational project for teaching optics and photonics. ALOP has had strong acceptance in Colombia where there have been successfully carried out four workshops and others are expected to continue in the short and medium term.

The active learning method consist of allowing the student to build their own knowledge from conducting simple experiments and compare the results obtained with the preconceived idea that the student may have had about the phenomenon observed. In this process the teacher plays the role of guide and facilitator of learning and the directed activity replaces traditional explanation. A feature of the workshops proposed by UNESCO, in addition to implementing the active learning method, is that they do it through laboratories that require for their accomplishment inexpensive and fairly easy to achieve and / or reproducibility material. The workshop introduces participants to the basics of optics and photonics including vision and their correction, interference and diffraction phenomena, atmospheric optics and innovative applications as fiber optic communications. The workshop is divided into 6 modules namely: (1) geometric optics, (2) eye optical lenses, (3) Interference and Diffraction, (4) Atmospheric Optics, (5) Optical data transmission (6) Multiplexing division wavelength.

\section{COLOMBIAN EXPERIENCE}

\subsection{ALOP-BOGOTA-2009: THE FIRST CHALLENGE}

In early 2009 the National University of Colombia through the Faculty of Science, asked UNESCO to host a workshop ALOP. This workshop was held in June 2009 in the Department of Physics at the Bogota headquarters of the National University of Colombia and was attended by international facilitators 9, 4 of them Spanish- speaking, a UNESCO representative and student participation of 7 academics from the region (Guatemala, Venezuela, Peru and Bolivia) 18 Colombian universities teachers and 13 middle school teachers from public schools in Bogotá.

In the final evaluation, participants highlighted as favorable facts of the workshop, among others, the methodology used on it enabling them to significantly increase their understanding of optics and photonics, quality, clarity, and willingness of the facilitators, facility in the material reproduction of almost all modules allowing them to bring the experience to their classroom. As a negative fact it was emphasized almost unanimously that the workshop had been conducted in

12th Education and Training in Optics and Photonics Conference, edited by

Manuel F. P. C. Martins Costa, Mourad Zghal, Proc. of SPIE Vol. 9289, 92890Y

(c) 2014 SPIE, OSA, IEEE, ICO · doi: 10.1117/12.2070744 
English, the lack fluency in English of the participants was often a constraint to interact with facilitators and the need of translation made discussion slow.

The workshop ALOP-Bogotá 2009 had financial support from several international institutions (UNESCO, ICTP, OSA, NAS-USA, SPIE, ESSILOR) and national (National University of Colombia, Colombian Academy of Exact, Physical and Natural Sciences) as well as support from the university of origin of the facilitators and participants.
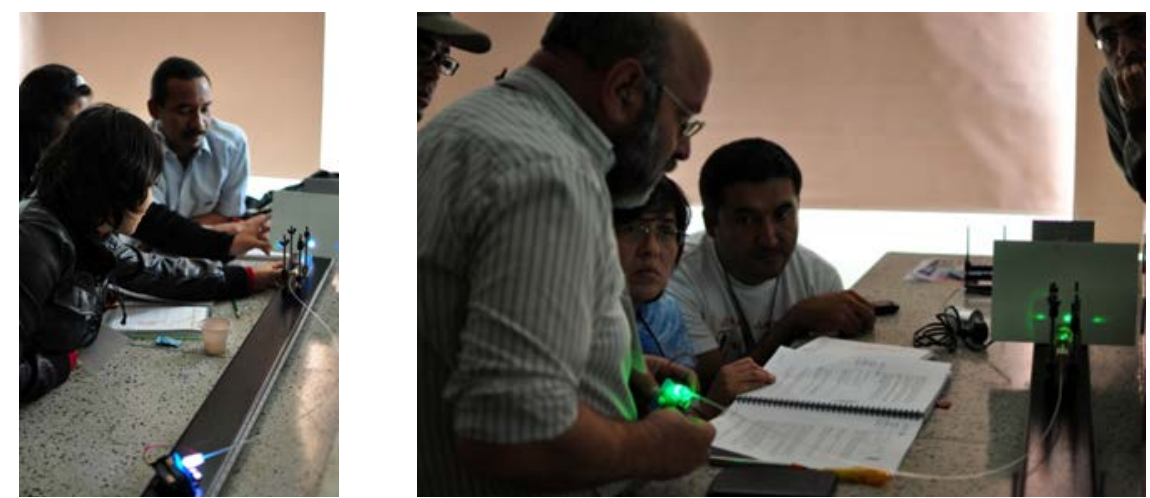

Figure 1: Some participants in ALOP-Bogota-2009

The experience acquired by the National University professors who participated in ALOP-Bogotá reversed in the Master of Teaching Natural Sciences, a program aimed at teachers of primary and secondary education, which was opened in the second half of 2009 and is training over 400 teachers across the country. This program provides middle school teacher training that integrates both solid disciplinary knowledge of scientific content in the natural sciences (Mathematics, Statistics, Physics, Chemistry, Biology, Geosciences, Astronomy) and teaching strategies that allow teaching this content with the means available and appropriate to the characteristics of their environment. At the same time, the program aims to train teachers to be able to create and evaluate their own teaching strategies, to upgrade themselves and to establish academic networks that support their work.

\subsection{ALOP-BOGOTA - 2010: WORK BEGINS WITH NPH}

The National University of Colombia, has eight headquarters of which four are located in large and intermediate cities: Bogota, Manizales, Medellin and Palmira and the remaining four called National Presence Headquarters (NPH) which are Amazon (Leticia), Caribbean (San Andres Island and Valledupar), Orinoco (Arauca) and Tumaco.

Border regions in which are located the $N P H$, are important for the University to the extent that they converge aspects such as a privileged geostrategic position, significant presence of Afro-Colombians and indigenous ethnic groups and high biodiversity in their ecosystems. However, despite the high potential of development on these regions, their background has a high index of unsatisfied basic needs, low levels of education expressed in terms of coverage and quality as well as a very weak state presence.

For National University it is essential the improvement of education in the border areas, for which it has carried out various activities from the National Presence Headquarters which stand on the one hand, the enormous effort to facilitate access to higher education to graduates of border regions through SPAAM (Special Program of Admission and Academic Mobility) and second, the community outreach through various agreements and upgrade programs for teachers of secondary and early college levels made with the company of the department of education on each of the regions. This $A L O P$ was held in Bogota and had the presence of 8 facilitators (five facilitators from the National University of Colombia and 3 from abroad, all Spanish-speaking), 30 participants from the different offices of the National University and 8 special guests from the municipality of Tumaco (4) and the Department of Caesar (4). Each participant had a preliminary version of the training manual in Spanish, so that the workshop was held in Spanish, disappearing language difficulties that arose in ALOP-Bogotá 2009. 

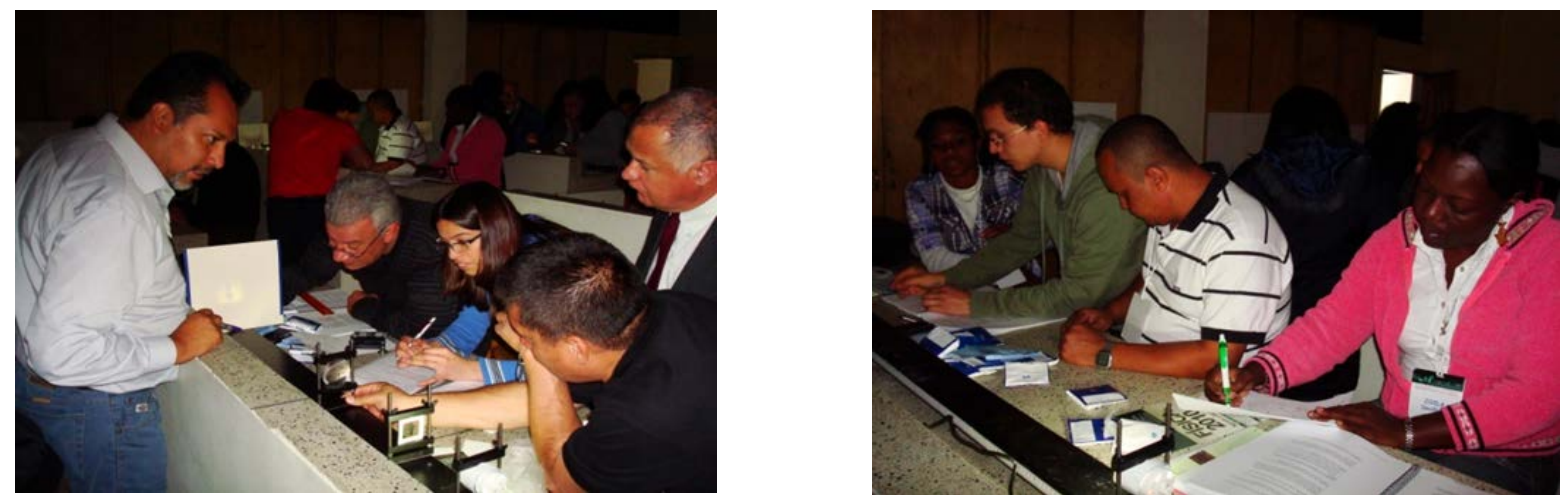

Figure 2: Some participants in Bogotá ALOP-NPH-2010

\subsection{ALOP-2011: MEDELLIN}

In 2011 ALOP workshop was held in Medellin and this time the material was built in partnership between Bogota and Medellin headquarters, and therefore we have two headquarters with capacity to produce at least the first four modules. This time we had the presence of two international and four national facilitators, from this, it could be inferred that Colombian team facilitators was consolidated. With this $A L O P$ were benefited middle school teachers in the region of Antioquia, students of the Master of Teaching Natural Sciences and Physical Engineering students Medellin headquarters.

\subsection{ALOP-NPH-2013: NPH CARIBBEAN AND TUMACO}

The ALOP-NPH-Caribbean was held in Caribbean headquarters of the National University of Colombia located on the island of San Andrés, between 21 and 25 January 2013, on this occasion 13 teachers attended from different secondary institutions of the island and the Medellin headquarters of the National University of Colombia. This workshop had 2 international and 3 national facilitators.
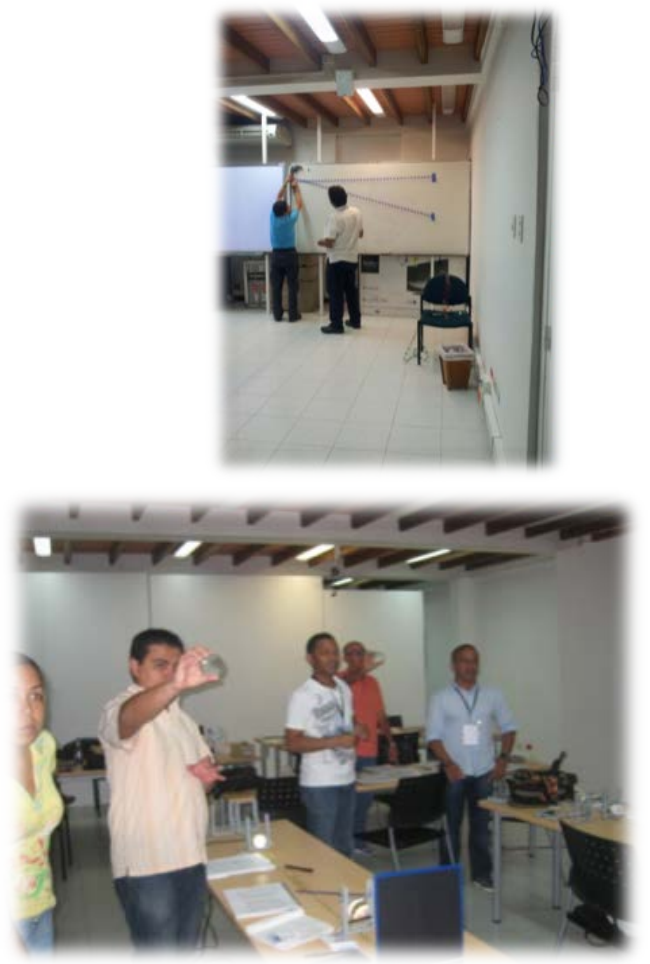
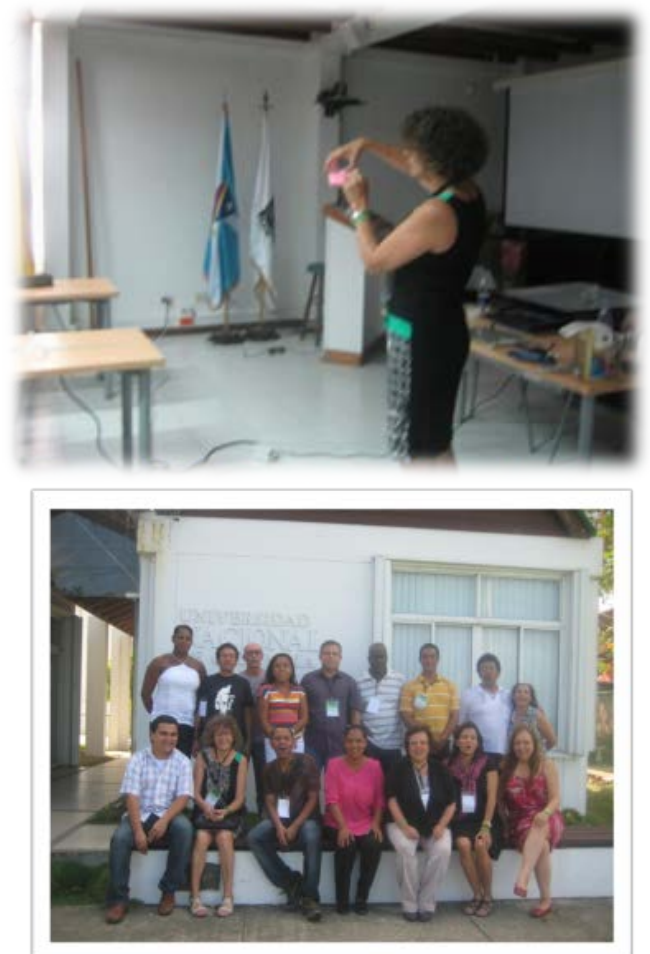

Figure 3: Some facilitators and participants in the Caribbean ALOP-NPH-2013 
The financial support for conducting this workshop and Tumaco's workshop was obtained by the Solidary extension project "ALOP-Active Learning in Optics and Photonics-A UNESCO's program spreading in Colombia through the National University: reproduction location NU Caribbean and Tumaco" from the direction of extension of Bogotá and the Faculty of Science of the National University of Colombia, where 33 projects were selected from 140 participants. Besides academic activities and workshops as part of $A L O P-N P H$, Caribbean headquarters featured several cultural events. The material and equipment used on this occasion was made entirely by the facilitators and the team of Bogotá National University of Colombia.

The ALOP-NPH Tumaco will be held in the city of Tumaco on the Colombian Pacific coast, which is one of the poorest regions of the country and will take place in the week of October $7^{\text {th }}-11^{\text {th }}, 2013$, the facilitators will be two international teachers and three national.

\section{OUR WORK ON THE ELECTRONIC DEVICES AND SUPPLIES}

Almost all equipment required for the ALOP-Bogotá 2010 was built locally by the facilitators and the auxiliary student team from the National University of Colombia. Initially we conducted a replication of equipment for the six modules donated by UNESCO in 2009 ALOP using local trade stocks. The international facilitators were in constant contact with local facilitators contributing their ideas and experience in team building and preparation of the workshop. Almost all the equipment needed for the modules 1 to 4 was found in local trade Bogotá and its preparation was relatively simple. However, it was necessary to import some elements such as polarizers, diffraction gratings and prisms.
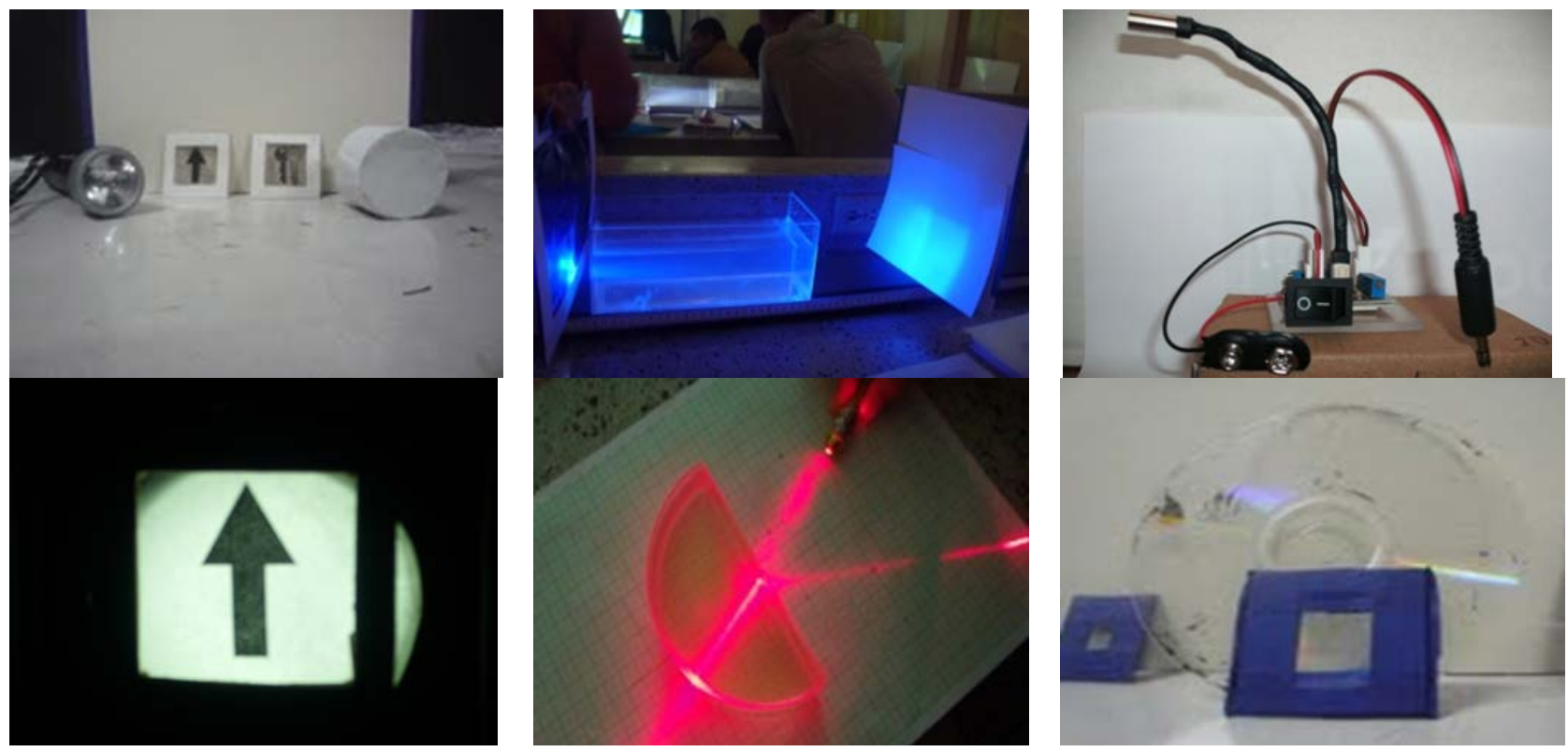

Figura 4: Algunos elementos construidos para ALOP-Bogotá-2010

About the material of the optical transmission modules and data division multiplexing wavelength, there was a first intervention that was tested in the ALOP-MEDELLIN-2011 which basically consisted of a redesign of some of the electronic circuits using the ORCAD 9.2 ${ }^{\circledR}$ software, ensuring that the new design perform at least the same function as the original device [1].

Some of the interventions aimed at electronic devices were:

1. Optical telegraph: This device comprises a transmitter which sends signals pulsed light to a receiver that takes and converts them into an audible signal, this included an NPN transistor [2] and a resistor, the first for amplifying and the second to polarize the transistor, this so the buzzer receives a $8.3 \mathrm{~V}$ voltage (since the battery is $9 \mathrm{~V}$ ). 
2. Wavelength multiplexing device [3,4]: Using this device it is sent via optical fiber and simultaneously several signals by an optical system, including a high-refractive power lens and a diffraction grating which area separated and taken by different receivers. As receiver it is used the same one designed for the optical telegraph, as transmitter it is used a RGB LED controlled so that it can emit different signals in predefined sequences. The original design uses a fixed programming microchip which was replaced by the CPLD module. The module CPLD (Complex Programmable Logic Device), is responsible for managing the programming LED. The CPLD is a reprogrammable device with large capacity, which allows its programming through parallel cable (JTAG) using the VHDL language. With this we get a device less sensitive to external electromagnetic fields, and possible to be reprogrammed according to use and needs.

3. All circuits have been modified to operate at 9 volts. This change was made in order to facilitate handling of the circuits. For this it was necessary to recalculate the values of some of the electronic components. The redesign includes a detachable connection to the battery, thus avoiding damage to the terminals of these.

4. To give greater protection against a possible short circuit in the card, and avoid unnecessary battery, it was installed a switch on each circuit.

5. In addition to electronic devices it was constructed fiber support, circuit-fiber, couplers, lens holder and support for the diffraction grating.

Based on the experience gained in the development of $A L O P$ workshops 2010 and 2011 and thinking about the future, is redesigned and fully optimized electronic equipment and as a result we obtained the following improvements:

1. It is replaced the batteries by power adapters that are more reliable when making practices. However removable connectors are provided which allow the use of batteries.

2. It is standardized the size of all the circuits and assembled into boxes that facilitate its use in practice and also serve as cases for protection of the same.

3. In the laser audio receiver circuit is implemented an audio amplifier with a speaker that allows to skip the need to use an external amplifier.

4. It is improved support for the diffraction grating which now includes the optical condenser and support for optical fiber.

5. It is completely encoded the sequence of colors present in the manual and it is programmed a very economical microcontroller as proposed by the creators of the $A L O P$.
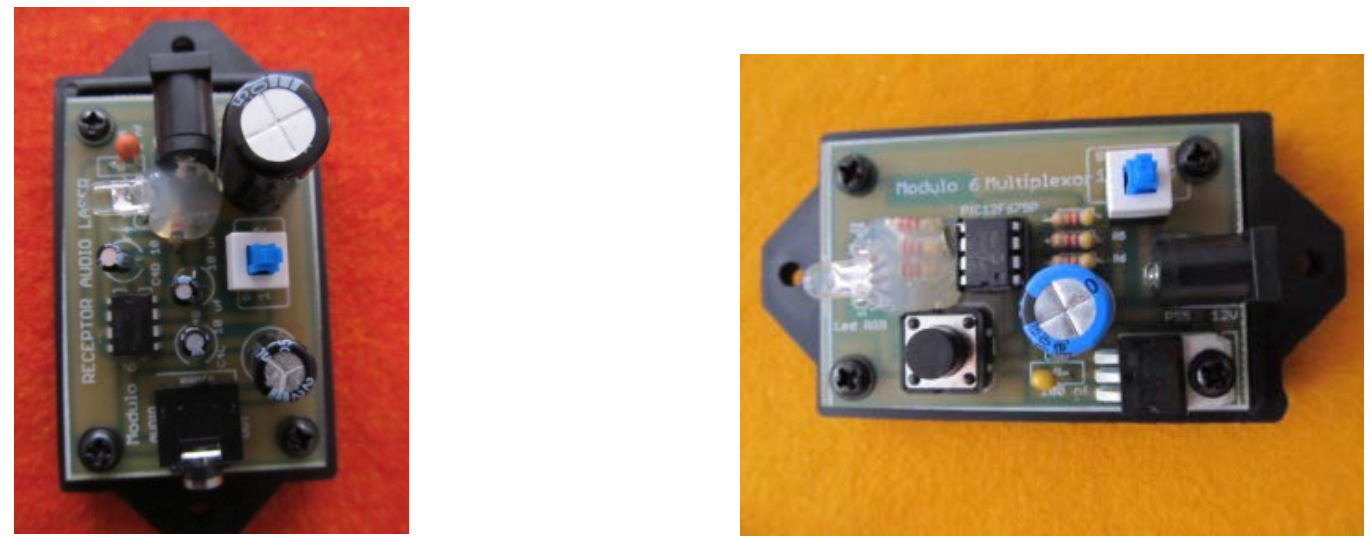

Figure 5: Some devices redesigned to ALOP-2013-ENG. Modules, Optical data transmission, Wavelength-division multiplexing. 


\section{ALOP-NPH IMPACT}

$A L O P-N P H$ has provided all the headquarters of the National University of Colombia with the chance that some of their teachers could be upgraded and formed with a new optical teaching methodology, methodology also applied to other areas of knowledge.

The involvement of teaching assistants from SPAAM program of Locations Caribbean, Orinoco and Amazon allowed them not only their upgrade, but also to establish contact with teachers of the central headquarters of the University with whom they can work now together on the implementation of the active learning method. This will benefit students in the program, which will get their headquarters better prepared.

The Master of Teaching of exact natural and sciences was doubly benefited by ALOP-NPH: first, several teachers of the program both Bogota and Medellin, and in different areas-physics, chemistry, biology and pedagogy, actively participated and showed interest in implementing active learning method from different disciplines, on the other hand, students in the program, from different cities and disciplines, attended the workshop and were trained in the method.

The presence of international facilitators and their ongoing support and constructive criticism of the work of local facilitators, leaves behind a team of trainers able to perform autonomously workshops in the country, including local construction of the equipment required and support to ALOP-Latin team if it requires of it.

Until the second half of 2012 it has been developed five final works in the Master of Teaching of extract natural and social sciences and there are 3 others in the process. They all are using the Active Learning Methodology on issues not only optical, but also mechanical and chemical and under the direction of one of the local facilitators or attendant of some of the workshops.

\section{OUTLOOK}

From the above it is clear that the $A L O P$ experience in Colombia has been entirely successful, however given the large number of secondary teachers in the country and the missionary work of the University of Colombia, as prospects it must not only continue with the improvement of materials, devices and equipment used in workshops, but also continue to expand its coverage across our country.

\section{REFERENCES}

[1] Poveda, I., and Gonzalez, D, (2011), 'Modification and adaptation of electronic circuits used in optical data transmission and division multiplexing wavelength in the workshops' Active Learning in Optics and Photonics ALOP " - private communication.

[2] Vishay Semiconductors, "BPV11, Silicon NPN Phototransistor Datasheet" can be downloaded from: http://www.vishay.com/docs/81504/bpv11.pdf.

[3] A.P. Mazzolini and P. J. Cadusch, "A single low-cost demonstration of wavelength division multiplexing," Am J Phys 74, 2006.

[4] National Semiconductor, "LF353, Wide Bandwith Dual JFET Input Operational Amplifier, Datasheet", download from: http://www.national.com/ds/LF/LF353.pdf. 